Article

\title{
Modelling the Optical Properties of Soot Particles under Various Aging Conditions
}

\author{
Kangwei Li ${ }^{1,2,3, * \mathbb{C}}$, Mingming Yan ${ }^{2}$, Jiandong Shen ${ }^{4}$, Xin Zhang ${ }^{2}$, Chunmei Geng ${ }^{1, *}$, \\ Wen Yang ${ }^{1}$ and Merched Azzi ${ }^{3}$ \\ 1 State Key Laboratory of Environmental Criteria and Risk Assessment, Chinese Research Academy of \\ Environmental Sciences, Beijing 100012, China; yangwen@craes.org.cn \\ 2 State Key Laboratory of Clean Energy Utilization, Zhejiang University, Hangzhou 310027, China; \\ yanmingming@zju.edu.cn (M.Y.); 21860063@zju.edu.cn (X.Z.) \\ 3 CSIRO Energy, P.O. Box 52, North Ryde NSW 1670, Australia; Merched.Azzi@csiro.au \\ 4 Hangzhou Environmental Monitoring Center Station, Hangzhou 310007, China; sjiandong@gmail.com \\ * Correspondence: likangweizju@foxmail.com (K.L.); gengcm@craes.org.cn (C.G.)
}

Received: 2 December 2019; Accepted: 7 January 2020; Published: 10 January 2020

check for updates

\begin{abstract}
As atmospheric fresh soot particles age, they become coated with other chemical species. This transforms their physicochemical properties and affects their optical characteristics, which is of great importance to air quality, the environment and climate change. One of the predominantly occurring states of soot particles in the ambient environment is the core-shell mixing state. In this study, we used the core-shell model to calculate the optical absorption, scattering and extinction efficiency, absorption proportion and absorption exponent of coated soot particles. We then investigated the effects of different core sizes $\left(D_{0}\right)$, incident wavelengths $(\lambda)$, coating materials and coating thicknesses on these optical characteristics. Absorption efficiency and absorption proportion of soot particles decreased as the coating became thicker, at core sizes of $D_{0}=20,50$ and $100 \mathrm{~nm}$ and $\lambda=405,532$ and $781 \mathrm{~nm}$, regardless of the type of coating material. As the coating thickness increased, the absorption exponent $(\beta)$ of inorganic-coated soot particles tended to rise and then fall, while the $\beta$ value of organic-coated soot particles kept increasing. Our results advance our scientific understanding of the interaction of optical properties with chemical composition, mixing state, and aging processes of soot particles in the atmosphere.
\end{abstract}

Keywords: core-shell model; optical property; soot particle; absorption efficiency; absorption exponent; coating composition

\section{Introduction}

Fresh soot particles can be as seed particles in the atmospheric aging process, where these secondary species from complex photochemical reactions with volatile organic compounds (VOCs), $\mathrm{SO}_{2}$, and NOx can be coated onto soot particles depending on the aging conditions [1,2]. Previous studies have demonstrated that the optical absorption of soot particles can increase after being coated with organic species [3,4]. For example, Cui et al. (2016) found that the aerosol light absorption at $678 \mathrm{~nm}$ increased by $30 \%$ after coating materials onto fresh soot particles [5]. Wang et al. (2014) measured the optical properties of atmospheric particles in Xi'an. They showed that the fraction of coated organic compounds onto soot particles increased significantly during heavily polluted periods, and that light absorption at $870 \mathrm{~nm}$ increased almost three times due to the coatings of internal mixed soot particles [6]. These studies indicate that coating materials can change the optical properties of soot particles during the chemical aging process and increase their light absorption at different wavelengths compared with fresh soot particles. 
The absorption exponent $(\beta)$ is a physical parameter that describes the absorption capacity of carbon-containing particles as a function of wavelength. Generally, the $\beta$ value of carbon-containing particles rises as the amount of organic coating increases. Therefore, $\beta$ can be used as an indicator of the degree of aging of soot particles. Previous studies related to the physical and chemical properties of soot aging processes focused primarily on particle morphology, effective density, light absorption and scattering properties at a specific wavelength. For example, strong absorptive species, such as soot particles, have optical absorption capacities within the ultraviolet-infrared spectrum [7], while the optical absorption capacity of weakly absorbing materials (e.g., brown carbon) is mainly concentrated at short wavelengths of violet. Soot particles with different internal mixing states also present different optical absorption properties [8]. A single-wavelength study can obtain the absorption and scattering properties of particles at a specific wavelength, while multiple wavelengths provide more in-depth information about the interaction between optical properties, mixed state and chemical composition of soot particles.

Besides to experimental measurement, modelling of the optical properties of soot particle aging process has also been performed under a variety of conditions previously. For example, Cheng et al. (2014) investigated the effects of atmospheric water on the optical properties of soot aerosols using a superposition T-matrix method under three different mixing states in the spectral range of 400-1020 nm [9]. They found that different mixing states with atmospheric water (e.g., externally mixed, semi-embedded mixed, and internally mixed) were responsible for the significant changes in the optical properties of soot aerosols. More recently, Doner et al. (2017) modelled the impact of necking and overlapping on the radiative properties of coated soot aggregates by using the Discrete Dipole Approximation (DDA) method [10]. They found that the calculated extinction, absorption, and scattering properties increased as overlapping and necking increased at four different wavelengths in the visible and near-infrared.

It has been well understood that the morphology of freshly emitted soot particles can be described as aggregates or chain-like structure, which consisted of hundreds of spherical primary particles with a certain degree of overlapping and necking between neighboring primary particles [11,12]. In some applications, coated soot aggregates are simply assumed to be single core-shell spheres and are calculated using the Mie method $[13,14]$. The basic assumption of the core-shell model is to approximate the soot particle as a concentric core-shell system or a homogeneous sphere. It should be noted that the core-shell model might be oversimplified and could lead to some inaccurate results in some conditions. For example, Liu et al., (2016) found that the core-shell model significantly overestimates the absorption enhancement by coating in the visible and the near-infrared compared to the Discrete Dipole Approximation (DDA) results of the coated soot particle [15]. Despite this, most climate models still employ the Mie method to calculate the radiative properties of coated soot particles primarily due to the simplicity of such treatments $[11,16]$.

The core-shell mixing state (fresh soot as the core) is one of the predominantly occurring states of soot particles in the atmosphere [17]. In this study, we used the core-shell theory model to simulate the optical properties of soot particles under different atmospheric aging conditions. The variation pattern of optical efficiency under various conditions is also discussed. We also investigated the effects of different coating materials, core size and coating thickness on absorption proportion and absorption exponent of soot particles. Together, our results provide a fundamental understanding of the interaction of optical properties with chemical composition, mixing state and aging processing of soot particles in the atmosphere.

\section{Methods}

\subsection{The Core-Shell Model}

The core-shell model, also known as the double-sphere model, assumes that the spherical core is insoluble and solid. Spherical coatings, such as inorganic or organic species, are assumed to be 
uniformly coated onto the core. As shown in Figure 1, the core diameter is $D_{0}$, and the refractive index (RI) of the core is $m_{1}=n_{1}-k_{1} \mathrm{i}$. The diameter of the coated particle is $D_{i}$, and the RI of the coating material is $m_{2}=n_{2}-k_{2}$ i. Note that $n$ and $k$ refer to the real and imaginary part of RI, and the above parameters are used as input for core-shell Mie calculation.

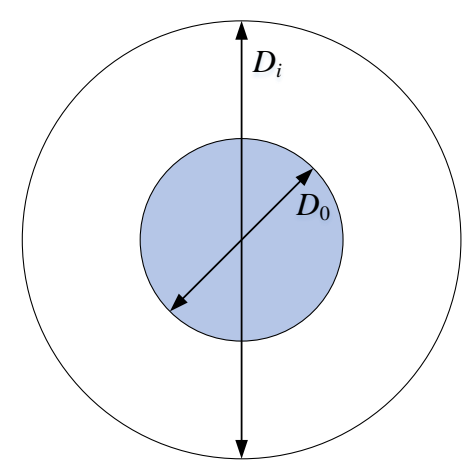

Figure 1. Core-shell model showing diameter of the core $\left(D_{0}\right)$ and the coated particle $\left(D_{i}\right)$.

According to the forward-scattering theory [18], the extinction $\left(Q_{\text {ext }}\right)$ and scattering $\left(Q_{\text {sca }}\right)$ efficiency of a double-layer sphere particle can be expressed as:

$$
\begin{aligned}
& Q_{e x t}=\frac{2}{y^{2}} \sum_{n=1}^{\infty}(2 n+1) \operatorname{Re}\left(a_{n}+b_{n}\right) \\
& Q_{\text {sca }}=\frac{2}{y^{2}} \sum_{n=1}^{\infty}(2 n+1)\left(\left|a_{n}\right|^{2}+\left|b_{n}\right|^{2}\right)
\end{aligned}
$$

The coated particle size parameter $(y)$ can be expressed as $y=\pi D_{i} / \lambda$, where $\lambda$ is the incident wavelength. The Mie coefficients of $a_{n}$ and $b_{n}$ can be expressed as [18]:

$$
\begin{gathered}
a_{n}=\frac{\left(D_{n} / m_{2}+n / y\right) \psi_{n}(y)-\psi_{n-1}(y)}{\left(D_{n} / m_{2}+n / y\right) \xi_{n}(y)-\xi_{n-1}(y)} \\
b_{n}=\frac{\left(m_{2} G_{n}+n / y\right) \psi_{n}(y)-\psi_{n-1}(y)}{\left(m_{2} G_{n}+n / y\right) \xi_{n}(y)-\xi_{n-1}(y)}
\end{gathered}
$$

In Equations (3) and (4), $\psi_{n}(y)=y j_{n}(y), \xi_{n}(y)=y h_{n}^{(1)}(y)$ and $\chi_{n}(y)=-y \cdot y_{n}(y)$ are Riccati-Bessel equations; $y_{n}(y)=\sqrt{\frac{\pi}{2 y}} Y_{n+0.5}(y)$ and $j_{n}(y)=\sqrt{\frac{\pi}{2 y}} J_{n+0.5}(y)$ are spherical Bessel equations; and $h_{n}^{(1)}(y)=j_{n}(y)+i y_{n}(z)$ is the spherical Hankel equation.

$D_{n}, G_{n}, A_{n}$ and $B_{n}$ can be expressed as:

$$
\begin{gathered}
D_{n}=\frac{D_{n}\left(m_{2} y\right)-A_{n} \chi_{n}^{\prime}\left(m_{2} y\right) / \psi_{n}\left(m_{2} y\right)}{1-A_{n} \chi_{n}\left(m_{2} y\right) / \psi_{n}\left(m_{2} y\right)} \\
G_{n}=\frac{D_{n}\left(m_{2} y\right)-B_{n} \chi^{\prime}{ }_{n}\left(m_{2} y\right) / \psi_{n}\left(m_{2} y\right)}{1-B_{n} \chi_{n}\left(m_{2} y\right) / \psi_{n}\left(m_{2} y\right)} \\
A_{n}=\psi_{n}\left(m_{2} x\right) \frac{m D_{n}\left(m_{1} x\right)-D_{n}\left(m_{2} x\right)}{m D_{n}\left(m_{1} x\right) \chi_{n}\left(m_{2} x\right)-\chi^{\prime}{ }_{n}\left(m_{2} x\right)} \\
B_{n}=\psi_{n}\left(m_{2} x\right) \frac{D_{n}\left(m_{1} x\right) / m-D_{n}\left(m_{2} x\right)}{D_{n}\left(m_{1} x\right) \chi_{n}\left(m_{2} x\right) / m-\chi_{n}{ }_{n}\left(m_{2} x\right)}
\end{gathered}
$$


where $x$ is the core size parameter with the expression of $x=\pi D_{0} / \lambda, m=m_{1} / m_{2}$. The absorption efficiency $Q_{a b s}$ can be expressed as:

$$
Q_{a b s}=Q_{e x t}-Q_{s c a}
$$

In this study, the Mie calculations were conducted using the existing MATLAB (version 2016) code developed by Mätzler (2002) [19]. To verify our modelling results, we simulated the extinction cross-section $\left(C_{\text {ext }}\right)$ for a single water-coated soot sphere under different coating thickness and compared it with the modelling results from Liu et al., (2012) [20]. Specifically, the refractive indices of soot and water used in Liu et al., (2012) are $m_{\text {soot }}=1.75-0.435 \mathrm{i}$ and $m_{\text {water }}=1.33-0 \mathrm{i}$ at incident wavelength of $628 \mathrm{~nm}$, and the core diameter of soot $\left(D_{0}\right)$ is $30 \mathrm{~nm}$ [20]. Here, we extracted the DMiLay result of the first-panel Figure 2 from Liu et al., (2012), and a similar case was modelled using the same parameters as core-shell model input [20]. Note that coating thicknesses $q$ in Liu et al., (2012) is converted to $D_{0} / D_{i}$ for comparison, which is $q=\left(D_{i}-D_{0}\right) / D_{0}$. The comparison result is shown in Figure $\mathrm{S} 1$, and both results were almost overlapped, which confirmed the reliability of the core-shell model used in this study to some extent.

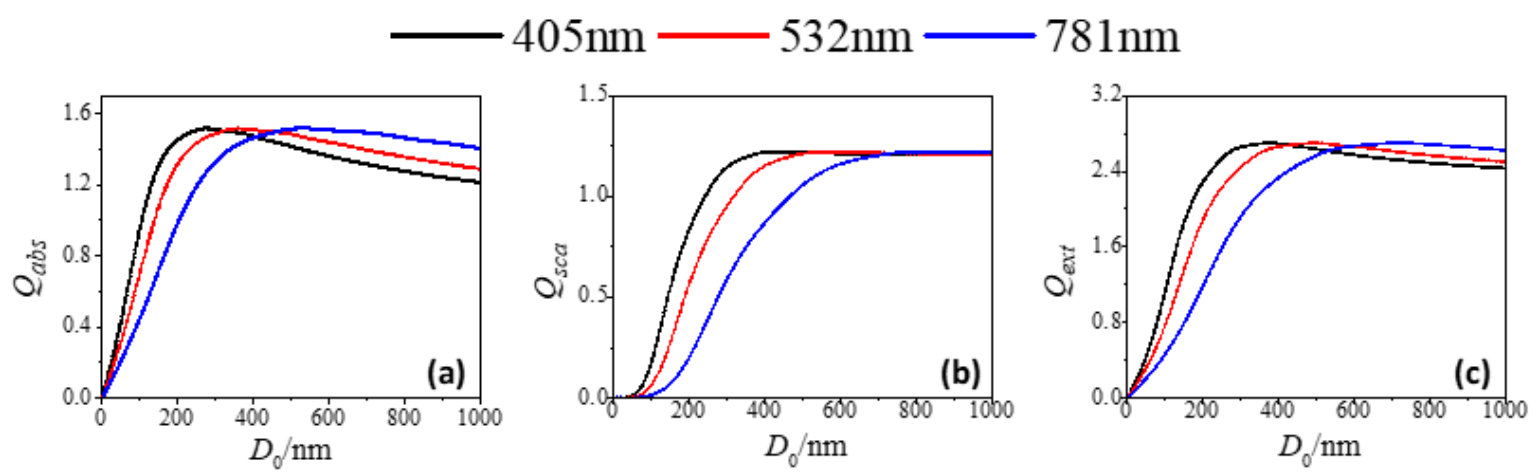

Figure 2. (a) Changes in absorption efficiency $\left(Q_{a b s}\right)$, (b) scattering efficiency $\left(Q_{s c a}\right)$ and (c) extinction efficiency $\left(Q_{e x t}\right)$ with soot particle core size $D_{0}$ at $\lambda=405,532$ and $781 \mathrm{~nm}$ (without coating material).

\subsection{The Derivation of Absorption Exponent $\beta$}

According to the literature [21], the absorption cross-section of a carbon-containing aerosol particle in the atmosphere has the following relationship with wavelength:

$$
C_{a b s, \lambda} \propto \lambda^{-\beta}
$$

In Equation (10), $\beta$ is the particle absorption exponent, which is related to the particle size and its RI.

For a single particle at a specific incident wavelength $(\lambda)$, the absorption cross-section $C_{a b s, \lambda}$ can be expressed as:

$$
C_{a b s, \lambda}=Q_{a b s, \lambda} \cdot \frac{\pi D^{2}}{4}
$$

where $D$ is the particle size, and $Q_{a b s, \lambda}$ is the absorption efficiency at a given incident wavelength $\lambda$.

According to Equation (10), there is

$$
C_{a b s, \lambda}=A \cdot \lambda^{-\beta}
$$

According to Equation (11), the absorption cross-section $\left(C_{a b s, \lambda}\right)$ of a single particle at multiple wavelengths can be calculated by the core-shell model, and then the particle absorption exponent $\beta$ can be obtained through the fitting of Equation (12). Figure S2 shows how the absorption cross-section of uncoated soot varies against the incident wavelength for a selected case, and the fitted parameter of absorption exponent $(\beta)$ can be obtained. 


\section{Results and Discussion}

Considering real atmospheric conditions, incident wavelengths of $405 \mathrm{~nm}$ (purple), $532 \mathrm{~nm}$ (green) and $781 \mathrm{~nm}$ (red) were selected in this study to cover the violet-infrared range, since the visible spectrum contains the major part of energy of the solar radiation. Also, according to the Mie theory, a particle scatters light more efficiently when the particle size and the incident wavelength are comparable. This means that the particle size range within accumulation mode is more efficient in scattering the solar radiation. Besides, these wavelengths are highly relevant to some commercial instruments for aerosol optical properties. For example, PASS-3 (three-wavelength photoacoustic soot spectrometer, Droplet Measurement Technologies Inc., CO 80503, USA) can measure aerosol light absorption at 405, 532 and $781 \mathrm{~nm}[22,23]$. This is another reason for choosing these wavelengths, which might be helpful for comparison with experimental measurements in the future.

The organic aerosol, ammonium sulfate, water as well as sea salt were typically observed as coatings onto soot particle in the real atmosphere. They been extensively investigated using transmission electron microscopy (TEM) and numerically modelling method in the previous studies. For example, Adachi and Buseck (2008) found that more than half of all particles contained soot coated by organic matter and sulfates in plumes of Mexico City [24]. Adachi et al., (2014) further found that a large amount of soot particles were internally mixed with non-volatile ammonium sulfate or other materials at a remote mountain site in Japan [25]. Soot particle could also be coated with sea salt aerosol in the marine environment, as evidenced by the observed internal mixtures of $\mathrm{NaCl}$ with soot aggregates in the Aerosol Characterization Experiment-2 (ACE-2) over the North Atlantic Ocean [26]. Scarnato et al., (2013) further investigated the morphology and mixing state of bare BC and $\mathrm{BC}$ internally mixed with sodium chloride $(\mathrm{NaCl})$ using electron microscopy and a discrete dipole approximation model [27].

In this study, four compositions $\left(\mathrm{H}_{2} \mathrm{O},\left(\mathrm{NH}_{4}\right)_{2} \mathrm{SO}_{4}, \mathrm{NaCl}\right.$ and weakly absorbing organic matter) were selected as the coating species of the soot particle to represent various aging conditions. The refractive indices of each material at different wavelengths are shown in Table 1. Note that the organic coating mentioned in this study has weak light-absorption property, which is generally similar to the "brown carbon". Brown carbon is defined as a light-absorbing carbonaceous material, which can absorb solar radiation, especially at ultraviolet (UV) and shorter visible wavelengths, and contribute to the radiation balance and photochemical reactions in the atmosphere $[28,29]$. Note also that the RI value for brown carbon is of high uncertainty, and it may vary from different VOC precursors or oxidation conditions. For simplification, we used a set of fixed RI values at three wavelengths for organic aerosol in this study, which are experimentally derived from toluene/NOx chamber experiments [23].

Table 1. Refractive index of core and coating material used for model calculation.

\begin{tabular}{ccccc}
\hline & \multicolumn{3}{c}{ Wavelength $\lambda / \mathbf{n m}$} & \multirow{2}{*}{ Reference } \\
\cline { 2 - 4 } & $\mathbf{4 0 5}$ & $\mathbf{5 3 2}$ & $\mathbf{7 8 1}$ & \\
\hline Soot & $1.57-0.56 \mathrm{i}$ & $1.57-0.56 \mathrm{i}$ & $1.57-0.56 \mathrm{i}$ & {$[30]$} \\
Water & $1.33-0 \mathrm{i}$ & $1.33-0 \mathrm{i}$ & $1.33-0 \mathrm{i}$ & {$[31]$} \\
$\left(\mathrm{NH}_{4}\right)_{2} \mathrm{SO}_{4}$ & $1.521-0 \mathrm{i}$ & $1.521-0 \mathrm{i}$ & $1.521-0 \mathrm{i}$ & {$[32]$} \\
$\mathrm{NaCl}$ & $1.54427-0 \mathrm{i}$ & $1.54427-0 \mathrm{i}$ & $1.54427-0 \mathrm{i}$ & {$[33]$} \\
Organics & $1.467-0.003 \mathrm{i}$ & $1.457-0.0004 \mathrm{i}$ & $1.403-0 \mathrm{i}$ & {$[23]$} \\
\hline
\end{tabular}

\subsection{Absorption Efficiency $Q_{a b s}$}

Figure 2a shows the absorption efficiency $Q_{a b s}$ of uncoated soot at different incident wavelengths, which were calculated from the core-shell model. Regardless of the incident wavelength $\lambda, Q_{a b s}$ increased sharply and then decreased slightly with the increase of core diameter $D_{0}$.

Figure 3 shows the variation in $Q_{a b s}$ with $D_{i} / D_{0}$ (an indicator of coating thickness) under different incident wavelengths $(\lambda)$ and core sizes $\left(D_{0}\right)$. This represents the aging process of fresh soot particles 
with initial size of $D_{0}$ under various coating materials. Note that the ranges of $D_{i} / D_{0}$ modelled in this study (1 10) is to cover a wide coating conditions, which is overall higher than that observed in some typical chamber experiments (e.g., 1 3 in the literature [4]). For an incident wavelength of 405 $\mathrm{nm}$ among different $D_{0}$ shown in Figure $3 \mathrm{a}-\mathrm{c}, Q_{a b s}$ of organic-coated soot was generally higher than the other three inorganic-coated soots, and the gap between both increased with an increase of $D_{i} / D_{0}$. This could be explained by the weak absorption effect (imaginary part of RI) of the organic coating. The absorption efficiency $Q_{a b s}$ of $\left(\mathrm{NH}_{4}\right)_{2} \mathrm{SO}_{4}$ and $\mathrm{NaCl}$-coated soot particles were almost equivalent, but slightly higher than the water-coated soot particles as $D_{i} / D_{0}$ increased, particularly for higher core sizes of 50 and $100 \mathrm{~nm}$.

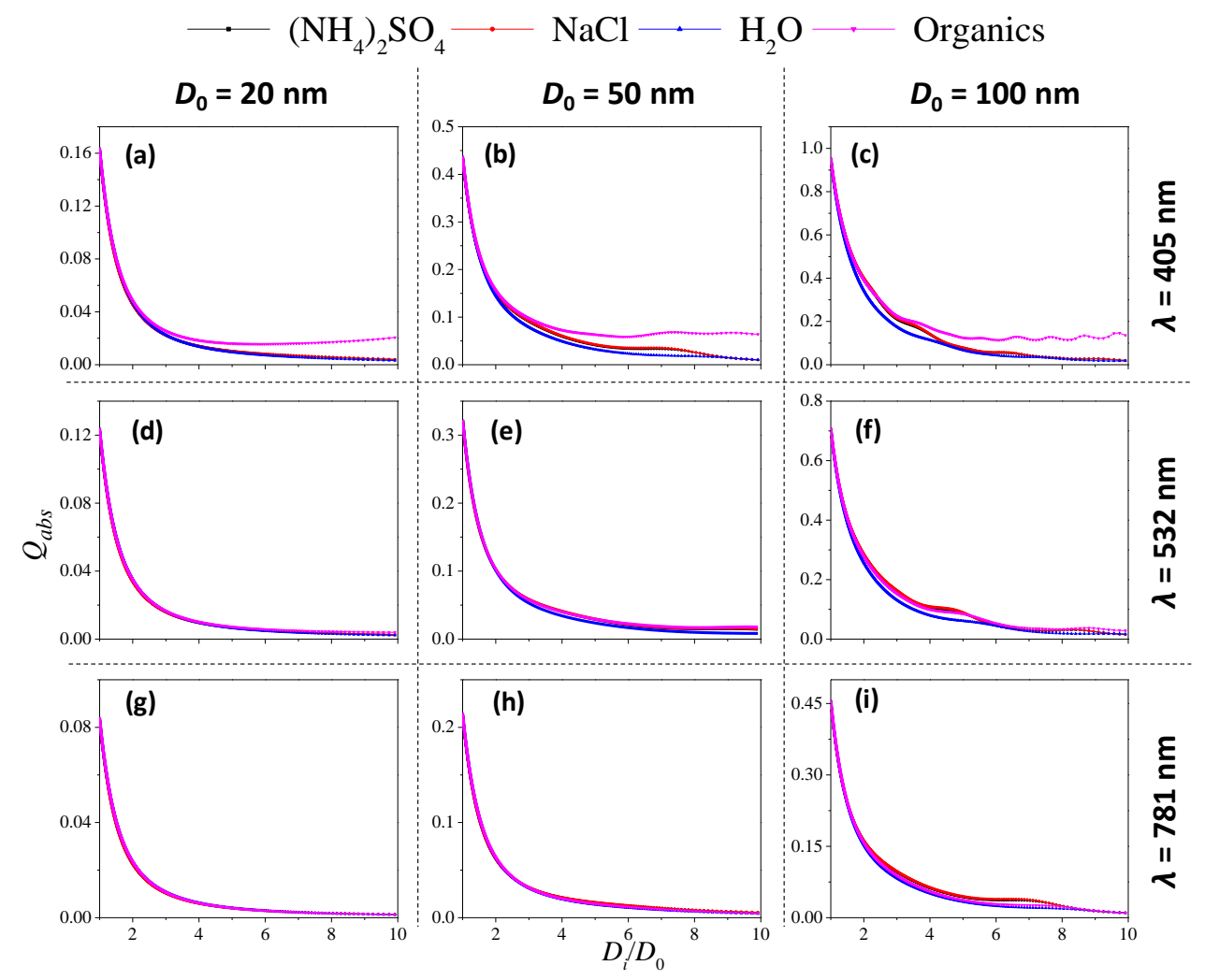

Figure 3. Variation in absorption efficiency $\left(Q_{a b s}\right)$ with coating thickness $\left(D_{i} / D_{0}\right)$ for various soot-particle coated materials $\left(\lambda=405,532\right.$ and $781 \mathrm{~nm}$; soot particle core diameter $D_{0}=20,50$ and $\left.100 \mathrm{~nm}\right)$. (a-c): $\left(\lambda=405 \mathrm{~nm}\right.$; soot particle core diameter $D_{0}=20,50$ and $\left.100 \mathrm{~nm}\right) ;(\mathbf{d}-\mathbf{f}):(\lambda=532 \mathrm{~nm}$; soot particle core diameter $D_{0}=20,50$ and $\left.100 \mathrm{~nm}\right) ;(\mathbf{g}-\mathbf{i}):\left(\lambda=781 \mathrm{~nm}\right.$; soot particle core diameter $D_{0}=20,50$ and $100 \mathrm{~nm}$ ).

Figure $3 \mathrm{~d}-\mathrm{i}$ show the variation of $Q_{a b s}$ with $D_{i} / D_{0}$ at incident wavelengths of 532 and $781 \mathrm{~nm}$, respectively. The decay curves of $Q_{a b s}$ against $D_{i} / D_{0}$ almost overlapped for all coating materials; this feature was observed for all core sizes from 20 to $100 \mathrm{~nm}$, suggesting that the coating composition is not sensitive to the absorption efficiency in green and red light. In addition, the absorption efficiency was reduced by more than $95 \%$ compared with the soot without coating $\left(D_{i} / D_{0}=1\right)$.

The absorption cross-section of a single particle (under a selected incident light) is equal to the absorption efficiency multiplying the cross-sectional area, which is described in Equation (11). Although Figure 3 shows that the absorption efficiency decreased significantly as coating thickness increased for all cases, the absorption cross-section still greatly increased. Figure S3 shows a simple example in which the absorption cross-section increased greatly as the coating of the soot particle became thicker. 


\subsection{Scattering Efficiency $Q_{s c a}$ and Extinction Efficiency $Q_{e x t}$}

Figure $2 b, c$ shows the variation in $Q_{s c a}$ and $Q_{e x t}$ of the uncoated soot particle with $D_{0}$. At different incident wavelengths, and with an increase of core size, both $Q_{s c a}$ and $Q_{e x t}$ increased sharply and then remained almost stable at the maximum value. Figure $4 a-c$ shows the variation of $Q_{s c a}$ against $D_{i} / D_{0}$ for different coating materials at an incident wavelength of $405 \mathrm{~nm}$. For $D_{0}=20 \mathrm{~nm}, Q_{s c a}$ increased with the increase of $D_{i} / D_{0}$, and the larger real part of the RI of coated soot tended to show a larger scattering efficiency. For $D_{0}=50 \mathrm{~nm}, Q_{s c a}$ generally increased with the increase of $D_{i} / D_{0}$, and $Q_{s c a}$ was significantly larger than that of $D_{0}=20 \mathrm{~nm}$. For $D_{0}=100 \mathrm{~nm}, Q_{s c a}$ generally increased first and then decreased with the increase of $D_{i} / D_{0}$. After $Q_{s c a}$ reached the maximum value, the variation of $Q_{s c a}$ for different-coated soot was determined by both the RI and coating thickness. In addition, the larger real part of the coating RI tended to show a larger maximum value of $Q_{s c a}$.

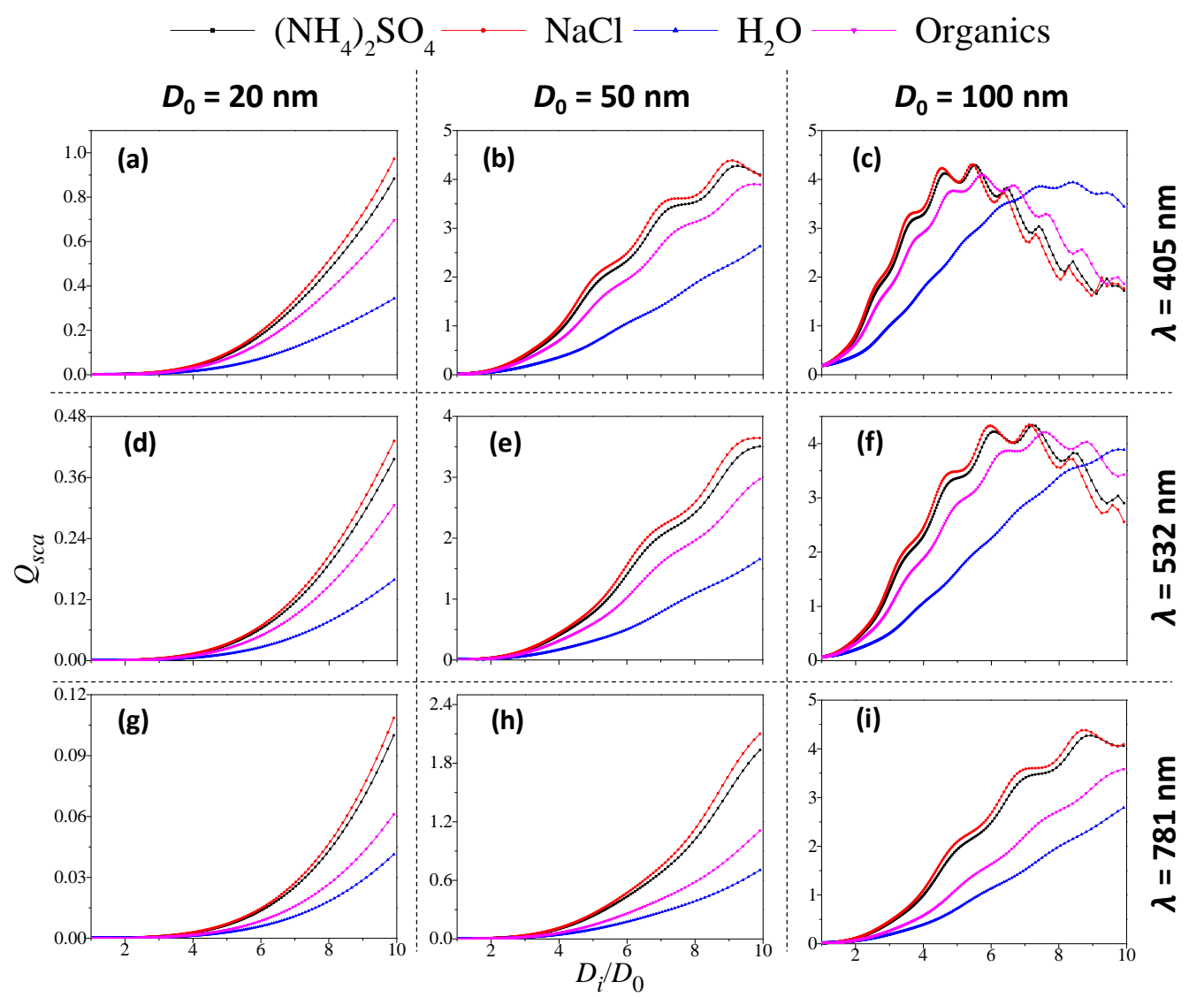

Figure 4. Variation in scattering efficiency $\left(Q_{s c a}\right)$ with coating thickness $\left(D_{i} / D_{0}\right)$ under various soot-particle coated materials $\left(\lambda=405,532\right.$ and $781 \mathrm{~nm}$; soot particle core diameter $D_{0}=20,50$ and $100 \mathrm{~nm}) .(\mathbf{a}-\mathbf{c}):\left(\lambda=405 \mathrm{~nm}\right.$; soot particle core diameter $D_{0}=20,50$ and $\left.100 \mathrm{~nm}\right) ;(\mathbf{d}-\mathbf{f}):(\lambda=532 \mathrm{~nm}$; soot particle core diameter $D_{0}=20,50$ and $\left.100 \mathrm{~nm}\right) ;(\mathbf{g}-\mathbf{i}):\left(\lambda=781 \mathrm{~nm}\right.$; soot particle core diameter $D_{0}$ $=20,50$ and $100 \mathrm{~nm}$ ).

Figure $4 \mathrm{~d}-\mathrm{i}$ show the variation in $Q_{s c a}$ with $D_{i} / D_{0}$ for different-coated soot at $\lambda=532$ and $781 \mathrm{~nm}$, respectively, which displayed a generally similar variation pattern to that at $\lambda=405 \mathrm{~nm}$. For a given core size (e.g., $D_{0}=20 \mathrm{~nm}$ ), $Q_{\text {sca }}$ tended to show the highest value at a short incident wavelength of 405 $\mathrm{nm}$, and lowest at a large incident wavelength of $781 \mathrm{~nm}$, regardless of coating material and thickness. The same phenomenon was observed for core sizes of $50 \mathrm{~nm}$ and $100 \mathrm{~nm}$.

Figure $5 \mathrm{a}, \mathrm{d}, \mathrm{g}$ show the variation pattern of $Q_{e x t}$ with $D_{i} / D_{0}$ for $D_{0}=20 \mathrm{~nm}$ at $\lambda=405,532$ and 781 $\mathrm{nm}$. Generally, $Q_{e x t}$ decreased first to the minimum value, and then increased with the rise in $D_{i} / D_{0}$ for all incident wavelengths. The highest $Q_{e x t}$ value was observed for $\mathrm{NaCl}$-coated soot, particularly 
at a large coating thickness $\left(D_{i} / D_{0}>5\right)$, which is the highest real part of RI among the four coating components. Figure $5 \mathrm{a}, \mathrm{d}, \mathrm{g}$ also shows that the extinction efficiency of soot particles generally grew higher as the incident wavelength increased.

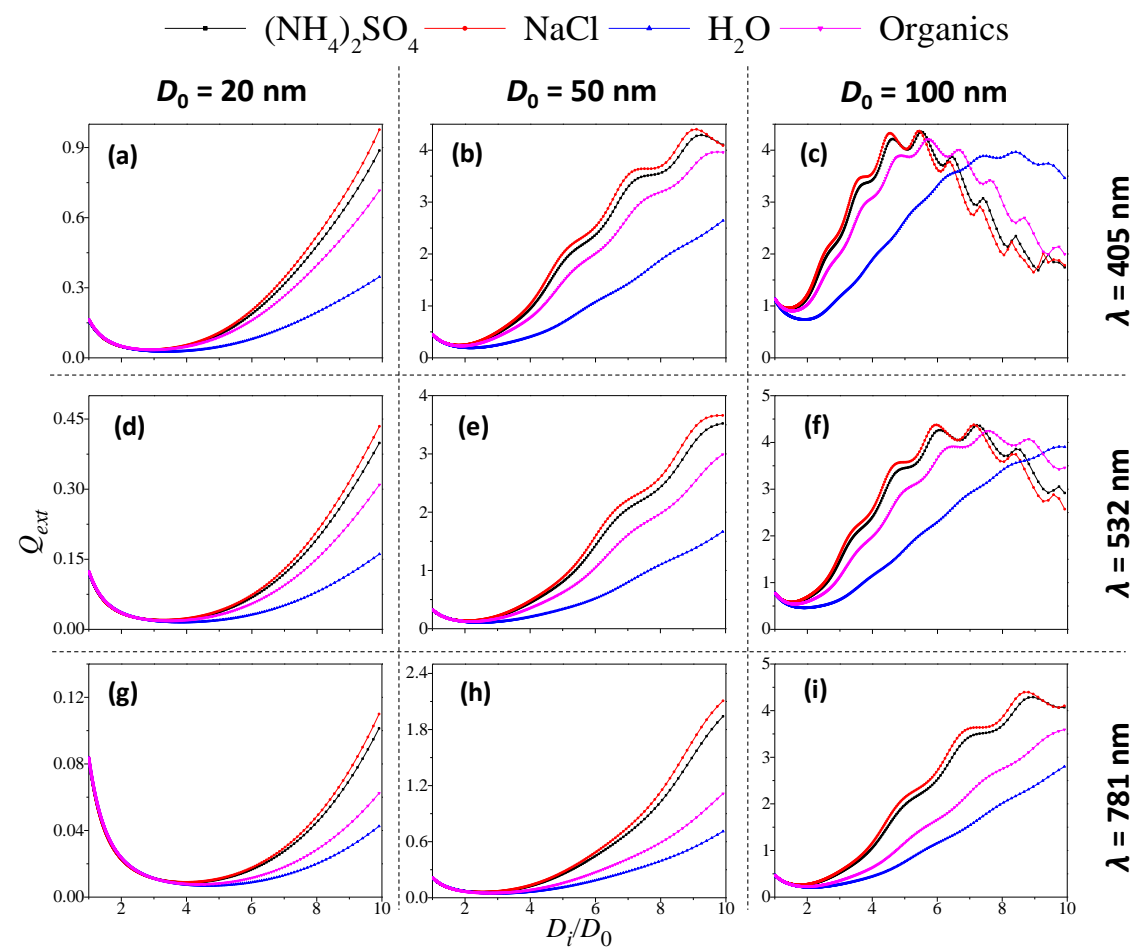

Figure 5. Variation in extinction efficiency $\left(Q_{\text {ext }}\right)$ with coating thickness $\left(D_{i} / D_{0}\right)$ under various soot-particle coated materials $\left(\lambda=405,532\right.$ and $781 \mathrm{~nm} ; D_{0}=20,50$ and $\left.100 \mathrm{~nm}\right) .(\mathbf{a}-\mathbf{c}):(\lambda=405 \mathrm{~nm}$; soot particle core diameter $D_{0}=20,50$ and $\left.100 \mathrm{~nm}\right) ;(\mathbf{d}-\mathbf{f}):\left(\lambda=532 \mathrm{~nm}\right.$; soot particle core diameter $D_{0}$ $=20,50$ and $100 \mathrm{~nm}) ;(\mathbf{g}-\mathbf{i}):\left(\lambda=781 \mathrm{~nm}\right.$; soot particle core diameter $D_{0}=20,50$ and $\left.100 \mathrm{~nm}\right)$.

Figure $5 \mathrm{~b}, \mathrm{c}, \mathrm{e}, \mathrm{f}, \mathrm{h}, \mathrm{i}$ show the variation in $Q_{\text {ext }}$ with $D_{i} / D_{0}$ for different-coated soot at $D_{0}=50$ and $100 \mathrm{~nm}$, respectively. The $Q_{e x t}$ values for almost all cases decreased slightly and then greatly increased as $D_{i} / D_{0}$ grew. Figure $5 \mathrm{c}, \mathrm{f}$ shows two specific cases for $D_{0}=100 \mathrm{~nm}$ at incident wavelengths of 405 and $781 \mathrm{~nm}$, where the $Q_{e x t}$ values increased to maximum and then fell. Except for these two cases, the $Q_{\text {ext }}$ values showed a similar variation pattern for all the remaining cases, similar as observed for $D_{0}=20 \mathrm{~nm}$. In addition, when the four coating materials were compared, the real part of coating RI determined the $Q_{e x t}$ level for the coated soot particle and followed the order of $\mathrm{NaCl}>\left(\mathrm{NH}_{4}\right)_{2} \mathrm{SO}_{4}>$ organic $>\mathrm{H}_{2} \mathrm{O}$, regardless of core size or incident wavelength.

\subsection{Absorption Proportion $\eta$ of Soot Particles}

The absorption proportion $\eta$ of a soot particle is used as an indicator for the capacity of aerosol light absorption, which is defined as:

$$
\eta=1-\frac{Q_{s c a}}{Q_{e x t}}=\frac{Q_{a b s}}{Q_{e x t}}
$$

Figure 6 shows the variation in the absorption proportion of uncoated soot with a core size $D_{0}$. As $D_{0}$ increased, the trend of $\eta$ decreased continuously: The smaller the incident wavelength, the faster the decay rate of $\eta$. In other words, when the uncoated soot particle was at a given size, large incident wavelengths always showed a higher $\eta$ value than did short incident wavelengths. 


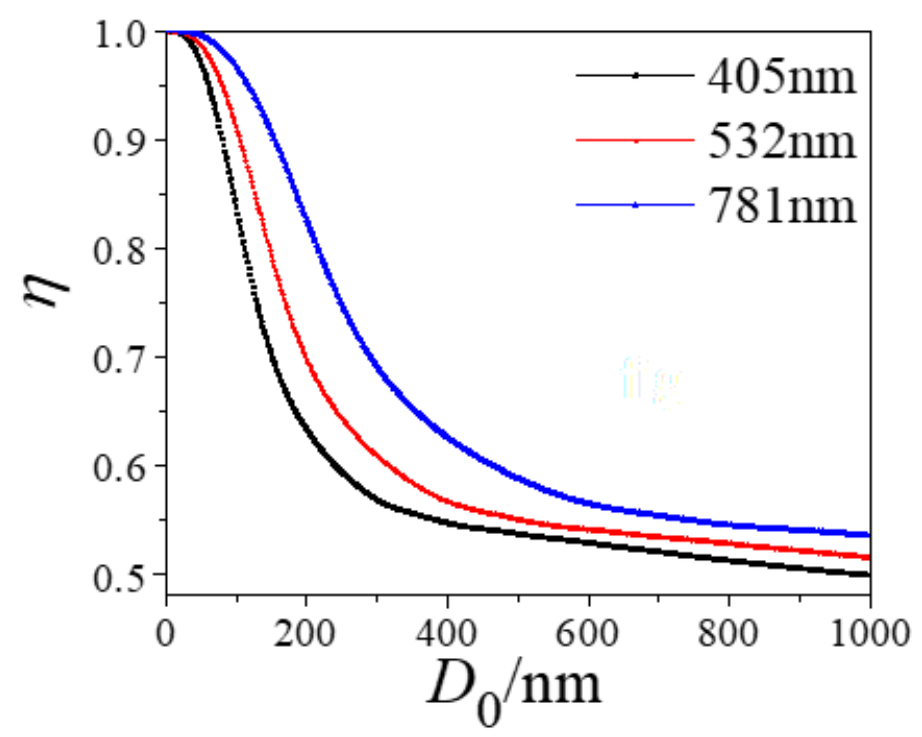

Figure 6. Changes in absorption proportion $\eta$ with core diameter $D_{0}$ for uncoated soot particles under various incident wavelengths.

Figure 7 shows the variation of the $\eta$ value with $D_{i} / D_{0}$ under different coating materials. The $\eta$ values decreased as $D_{i} / D_{0}$ increased in almost all cases, regardless of core diameter, incident wavelength or coating material. In addition, for all conditions, the decay rate of $\eta$ exhibited similar behaviour among the four coating materials, being the lowest for water-coated soot and the highest for inorganic-coated soot. This feature may be attributed to the difference in the real and imaginary parts of the RI.

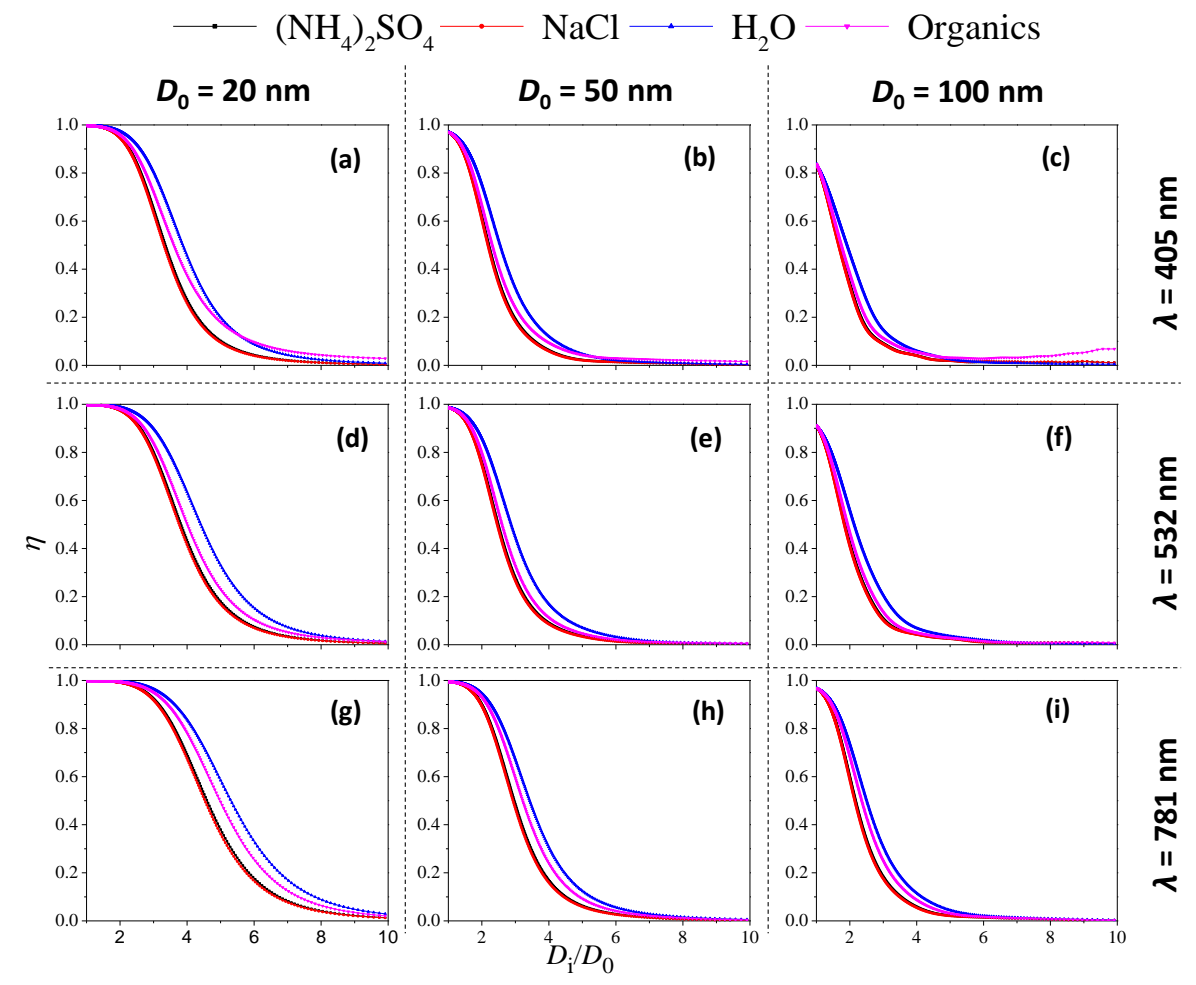

Figure 7. Variation in absorption proportion $\eta$ with coating thickness $\left(D_{i} / D_{0}\right)$ under various soot-particle coated materials $\left(\lambda=405,532\right.$ and $781 \mathrm{~nm}$; soot particle diameter $D_{0}=20,50$ and $\left.100 \mathrm{~nm}\right)$. (a-c): $\left(\lambda=405 \mathrm{~nm}\right.$; soot particle core diameter $D_{0}=20,50$ and $\left.100 \mathrm{~nm}\right) ;(\mathbf{d}-\mathbf{f}):(\lambda=532 \mathrm{~nm}$; soot particle core diameter $D_{0}=20,50$ and $\left.100 \mathrm{~nm}\right) ;(\mathbf{g}-\mathbf{i}):\left(\lambda=781 \mathrm{~nm}\right.$; soot particle core diameter $D_{0}=20,50$ and $100 \mathrm{~nm})$. 
As summarized in Table $1, n_{\text {sea salt }}>n_{\text {organic }}>n_{\text {water, }}$ which indicates that scattering is enhanced more by inorganic coating material than by water coating. Therefore, for a given condition (fixed core diameter and incident wavelength), soot particles coated with stronger scattering material (i.e., higher $n$ value of RI) will usually lead to a higher scattering proportion, which corresponds to a lower $\eta$ value. In addition, there is a clear shift to faster rates of $\eta$ decay as core diameter increases from 20 to $100 \mathrm{~nm}$, regardless of incident wavelength and coating material. As core diameter increased, the $\eta$ value approached zero at lower $D_{i} / D_{0}$.

To further investigate the relationship between $\eta$ and $D_{i} / D_{0}$, we performed a model sensitivity test by changing the real and imaginary part of RI for the coating material. Here, we take a core diameter of $50 \mathrm{~nm}$ at incident wavelength of $405 \mathrm{~nm}$ as an example. Figure 8 shows the variations in $\eta$ values against $D_{i} / D_{0}$, with RI values of $1.467-0.3 \mathrm{i}, 1.467-0.03 \mathrm{i}, 1.467-0.003 \mathrm{i}$ and $1.33-0 \mathrm{i}$, respectively. In all cases, the absorption proportion of soot decreased with the increase of $D_{i} / D_{0}$, approaching a stable level at higher coating thicknesses (e.g., $D_{i} / D_{0}>6$ ). When the real parts of the RI of the coating material were held at $1.467, \eta$ decay slowed under the scenario of a higher imaginary part of RI, which is associated with a higher $\eta$ value. For example, when the imaginary parts of RI are $0.003,0.03$ and 0.3 , the $\eta$ values at $D_{i} / D_{0}>6$ are $\sim 0.02, \sim 0.15$ and $\sim 0.5$, respectively. This behavior is reasonable, because absorption will take a dominant role as coating thickness increases, particularly for coating components with a higher imaginary part of RI.

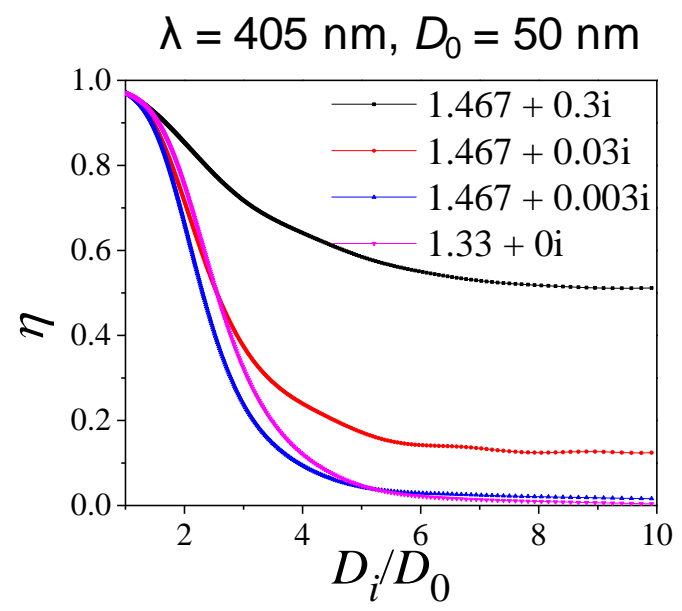

Figure 8. The changes in absorption proportion $\eta$ with coating thickness $\left(D_{i} / D_{0}\right)$ for various refractive indices of coating material.

\subsection{Absorption Exponent $\beta$}

The absorption exponent $\beta$ can describe the variation in absorption capacity with wavelength, which can indicate the aging degree of soot particles. Previous studies have shown that the $\beta$ value of fresh soot ranges from 0.8 to 1.2. Figure S4 shows the relationship between $\beta$ and $D_{0}$ of uncoated soot; the $\beta$ value first increases and then decreases, and the maximum value is 1.14 at $D_{0} \mathrm{of} 82 \mathrm{~nm}$. A minimum value of $\sim 0.8$ is obtained at a $D_{0}$ of $160 \mathrm{~nm}$, which is consistent with the descriptions in the literature [34,35].

Figure 9 a-c shows the variation of $\beta$ with $D_{i} / D_{0}$ at $D_{0}$ of 30,40 and $50 \mathrm{~nm}$. Overall, for organic-coated soot particles, $\beta$ kept increasing as the coating became thicker. However, for inorganic-coated soot, the $\beta$ value first increased and then decreased as coating thickness increased. This was observed for different $D_{0}$ values of 30,40 and $50 \mathrm{~nm}$. For a given core size $\left(D_{0}\right)$ and coating thickness $\left(D_{i} / D_{0}\right)$, the $\beta$ value of different coating materials followed the order: organic $>\mathrm{NaCl}>\left(\mathrm{NH}_{4}\right)_{2} \mathrm{SO}_{4}>\mathrm{H}_{2} \mathrm{O}$, which may be due to the difference in the real part of the RI. 

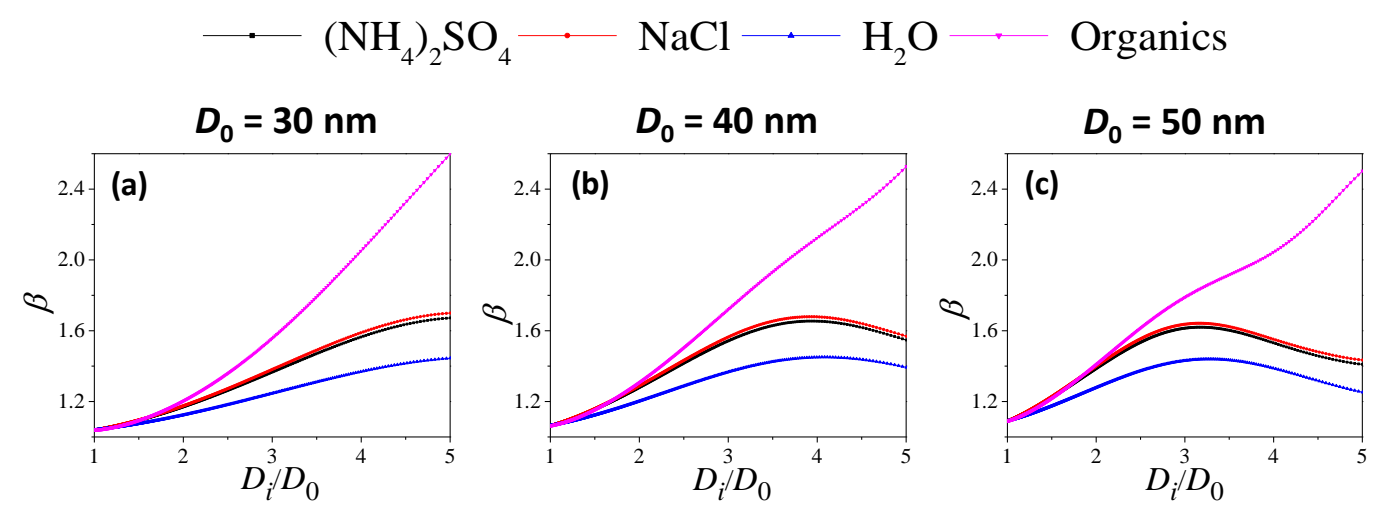

Figure 9. Variation in absorption exponent $\beta$ of coated soot particles with coating thickness $\left(D_{i} / D_{0}\right)$ for different coating materials $\left((\mathbf{a}-\mathbf{c})\right.$ : core size $D_{0}$ at $\left.30,40,50 \mathrm{~nm}\right)$.

Vehicle emissions are an important consideration for urban air pollution, particularly for diesel cars, as they emit soot particles as well as NOx and VOCs, which will contribute to the formation of secondary organic aerosol coating on fresh soot particles under sunlight $[36,37]$. From this perspective, we further investigate the variation in $\beta$ with $D_{i} / D_{0}$ under organic coating conditions. Figure 10 shows the relationship between $\beta$ and $D_{i} / D_{0}$ with $D_{0}$ of 30,40 and $50 \mathrm{~nm}$. A linear fitting describing the relationship between $\beta$ and $D_{i} / D_{0}$ within core size $30 \sim 50 \mathrm{~nm}$ is:

$$
\beta=0.349\left(D_{i} / D_{0}\right)+0.562
$$

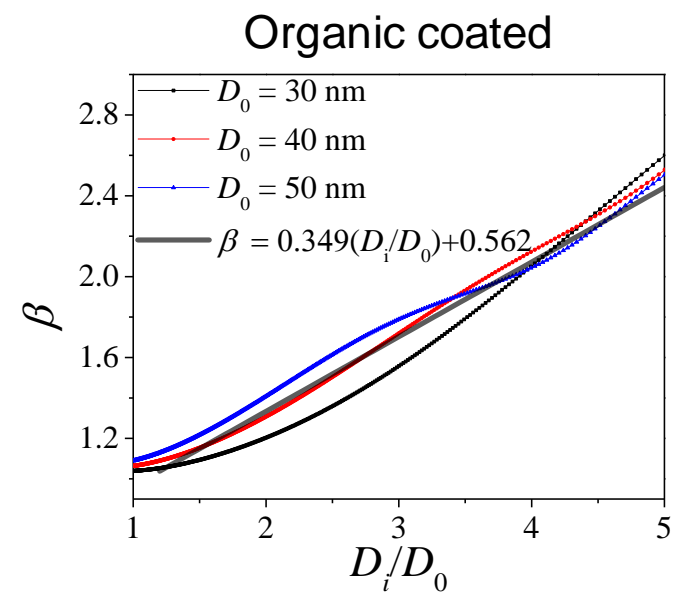

Figure 10. Relationship of absorption exponent $\beta$ with coating thickness $\left(D_{i} / D_{0}\right)$ for organic-coated soot particles (core size $D_{0}$ at $30,40,50 \mathrm{~nm}$ ).

Within a certain amount of estimation error, the relationship between the absorption exponent $\beta$ of organic-coated soot and $D_{i} / D_{0}$ can be approximately parameterized by the Equation (14). This is helpful for predicting soot aging degree under similar scenarios when direct measurement of $\beta$ is not available. However, it should be qualified more explicitly in the future work, as it depends strongly on the RI of the organic coating.

\section{Conclusions}

In this work, we used a core-shell model to simulate the optical properties of double-layer spherical soot particles coated with $\mathrm{H}_{2} \mathrm{O},\left(\mathrm{NH}_{4}\right)_{2} \mathrm{SO}_{4}, \mathrm{NaCl}$ and organic species under different aging conditions. Incident wavelengths of 405, 532 and $781 \mathrm{~nm}$ covering ultraviolet-infrared range were selected for model calculation. We investigated the variation in absorption efficiency $\left(Q_{a b s}\right)$, scattering efficiency 
$\left(Q_{s c a}\right)$, extinction efficiency $\left(Q_{e x t}\right)$, absorption proportion $(\eta)$ and absorption exponent $(\beta)$ with changes in core size $\left(D_{0}\right)$, coating materials, coating thickness $\left(D_{i} / D_{0}\right)$ and incident wavelengths $(\lambda)$. Our conclusions are as follows:

In uncoated conditions as $D_{0}$ increases, both $Q_{a b s}$ and $Q_{e x t}$ increase sharply and then slightly decrease, while $Q_{s c a}$ increases sharply and then stabilizes, regardless of incident wavelengths. In coated conditions as $D_{i} / D_{0}$ increases, $Q_{a b s}$ decreases while $Q_{e x t}$ generally increases. The type of coating materials, incident wavelengths and core size affect optical efficiency. For example, when the incident wavelength and core size are fixed, the $Q_{s c a}$ level of coated soot particles rises as the real part of the refractive index (RI) of the coating increases.

The $\eta$ of coated soot falls as $D_{i} / D_{0}$ increases for all core sizes, incident wavelengths and coating materials studied. The $\eta$ value of the coated soot is mainly controlled by the coating thickness, as well as the real and imaginary parts of the coating species' RI. For example, when the organic coating is thin, $\eta$ increases along with a rise in the real part of the RI of the organic coating. However, as the organic coating becomes thicker, the imaginary part of the RI of the organic coating leads to an increase in $\eta$.

The $\beta$ value of soot is also influenced by particle size and RI of the coating material. For soot particles coated with inorganic material, $\beta$ first increases and then decreases as $D_{i} / D_{0}$ rises, and coated soot particles with a larger real part of RI tends to show a higher $\beta$ value. For soot particles coated with organic material, the $\beta$ value keeps rising as the coating becomes thicker. For organic-coated soot particles with a core size of $30-50 \mathrm{~nm}$, we have determined the relationship between $\beta$ and $D_{i} / D_{0}$. This could be used to predict the degree of soot aging, particularly for diesel emissions, in which fresh soot particles are commonly mixed with organic aerosol.

Finally, our results provide some insights into the optical properties of soot-particle aging process. However, it is worth noting that there are still some limitations of this work, as the soot particle aging process was only modelled by a classic core-shell model for a few selected conditions. For future work, it is suggested to apply some advanced models (e.g., Discrete Dipole Approximation (DDA), Rayleigh Debye Gans (RDG) theory, etc.) and compare with the results from core-shell model. This could provide more insights on the scope of application of core-shell model. Besides, the core-shell model should be evaluated against experimental results, particularly from these well-designed and heavily-equipped smog chamber experiments, which could constrain the limitation of the core-shell model and provide more in-depth understanding on aerosol optical properties.

Supplementary Materials: The following are available online at http://www.mdpi.com/2073-4433/11/1/86/s1, Figure S1: Changes of extinction cross-section $\left(C_{\text {ext }}\right)$ with $D_{0} / D_{i}$ for water-coated soot. The refractive indexes of soot and water are $m_{\text {soot }}=1.75-0.435 i$ and $m_{\text {water }}=1.33-0 i$ at wavelength $628 \mathrm{~nm}$. The soot core diameter $D_{0}=$ $30 \mathrm{~nm}$. The core-shell model result is compared to the data extracted from Figure 2 in Liu et al., (2012), Figure S2: Changes in absorption cross-section $C_{a b s, \lambda}$ with $\lambda$ for fresh soot particles under selected conditions $\left(D_{0}=30 \mathrm{~nm}, \lambda\right.$ $=405,532$ and $781 \mathrm{~nm}$ ). This fitting curve shows an example for deriving the absorption exponent $\beta$ using the core-shell model, Figure S3: Changes in absorption cross-section $C_{a b s, \lambda}$ with coating thickness $\left(D_{i} / D_{0}\right)$ for coated soot particles under selected conditions $\left(D_{0}=20 \mathrm{~nm}, \lambda=405 \mathrm{~nm}\right.$, coated by $\left.\left(\mathrm{NH}_{4}\right)_{2} \mathrm{SO}_{4}\right)$, Figure S4: Variation in absorption exponent $\beta$ against core diameter $\left(D_{0}\right)$ for fresh soot particles without coating material.

Author Contributions: Conceptualization, K.L. and M.Y.; formal analysis, K.L., M.Y. and C.G.; methodology, M.Y. and X.Z.; project administration, K.L. and M.Y.; resources, K.L. and M.Y.; supervision, K.L.; writing-original draft, K.L.; writing-review \& editing, K.L., M.Y., J.S., C.G., W.Y. and M.A. All authors have read and agreed to the published version of the manuscript.

Funding: There is no financial funding for this work.

Acknowledgments: We would like to thank Hai Yu and Kathryn A. Kovac for the support of technical editing of this manuscript.

Conflicts of Interest: The authors declare no conflict of interest. 


\section{References}

1. Guo, S.; Hu, M.; Lin, Y.; Gomez-Hernandez, M.; Zamora, M.L.; Peng, J.; Collins, D.R.; Zhang, R. OH-initiated oxidation of m-xylene on black carbon aging. Environ. Sci. Technol. 2016, 50, 8605-8612. [CrossRef] [PubMed]

2. Schnitzler, E.G.; Dutt, A.; Charbonneau, A.M.; Olfert, J.S.; Jäger, W. Soot aggregate restructuring due to coatings of secondary organic aerosol derived from aromatic precursors. Environ. Sci. Technol. 2014, 48, 14309-14316. [CrossRef] [PubMed]

3. Schwarz, J.P.; Spackman, J.R.; Fahey, D.W.; Gao, R.S.; Lohmann, U.; Stier, P.; Watts, L.A.; Thomson, D.S.; Lack, D.A.; Pfister, L. Coatings and their enhancement of black carbon light absorption in the tropical atmosphere. J. Geophys. Res. Atmos. 2008, 113. [CrossRef]

4. Peng, J.; Hu, M.; Guo, S.; Du, Z.; Zheng, J.; Shang, D.; Levy Zamora, M.; Zeng, L.; Shao, M.; Wu, Y.; et al. Markedly enhanced absorption and direct radiative forcing of black carbon under polluted urban environments. Proc. Natl. Acad. Sci. USA 2016, 113, 4266-4271. [CrossRef] [PubMed]

5. Cui, X.; Wang, X.; Yang, L.; Chen, B.; Chen, J.; Andersson, A.; Gustafsson, Ö. Radiative absorption enhancement from coatings on black carbon aerosols. Sci. Total Environ. 2016, 551, 51-56. [CrossRef]

6. Wang, Q.; Huang, R.; Cao, J.; Han, Y.; Wang, G.; Li, G.; Wang, Y.; Dai, W.; Zhang, R.; Zhou, Y. Mixing state of black carbon aerosol in a heavily polluted urban area of China: Implications for light absorption enhancement. Aerosol Sci. Technol. 2014, 48, 689-697. [CrossRef]

7. Bond, T.C.; Bergstrom, R.W. Light absorption by carbonaceous particles: An investigative review. Aerosol Sci. Technol. 2006, 40, 27-67. [CrossRef]

8. Lack, D.A.; Langridge, J.M.; Bahreini, R.; Cappa, C.D.; Middlebrook, A.M.; Schwarz, J.P. Brown carbon and internal mixing in biomass burning particles. Proc. Natl. Acad. Sci. USA 2012, 109, 14802-14807. [CrossRef]

9. Cheng, T.; Gu, X.; Wu, Y.; Chen, H. Effects of atmospheric water on the optical properties of soot aerosols with different mixing states. J. Quant. Spectrosc. Radiat. Transf. 2014, 147, 196-206. [CrossRef]

10. Doner, N.; Liu, F.; Yon, J. Impact of necking and overlapping on radiative properties of coated soot aggregates. Aerosol Sci. Technol. 2017, 51, 532-542. [CrossRef]

11. Bond, T.C.; Doherty, S.J.; Fahey, D.W.; Forster, P.M.; Berntsen, T.; DeAngelo, B.J.; Flanner, M.G.; Ghan, S.; Kärcher, B.; Koch, D.; et al. Bounding the role of black carbon in the climate system: A scientific assessment. J. Geophys. Res. Atmos. 2013, 118, 5380-5552. [CrossRef]

12. Li, W.; Shao, L.; Zhang, D.; Ro, C.; Hu, M.; Bi, X.; Geng, H.; Matsuki, A.; Niu, H.; Chen, J. A review of single aerosol particle studies in the atmosphere of East Asia: Morphology, mixing state, source, and heterogeneous reactions. J. Clean. Prod. 2016, 112, 1330-1349. [CrossRef]

13. Shiraiwa, M.; Kondo, Y.; Iwamoto, T.; Kita, K. Amplification of Light Absorption of Black Carbon by Organic Coating. Aerosol Sci. Technol. 2010, 44, 46-54. [CrossRef]

14. Abo Riziq, A.; Trainic, M.; Erlick, C.; Segre, E.; Rudich, Y. Extinction efficiencies of coated absorbing aerosols measured by cavity ring down aerosol spectrometry. Atmos. Chem. Phys. 2008, 8, 1823-1833. [CrossRef]

15. Liu, F.; Yon, J.; Bescond, A. On the radiative properties of soot aggregates-Part 2: Effects of coating. J. Quant. Spectrosc. Radiat. Transf. 2016, 172, 134-145. [CrossRef]

16. Bauer, S.E.; Menon, S.; Koch, D.; Bond, T.C.; Tsigaridis, K. A global modeling study on carbonaceous aerosol microphysical characteristics and radiative effects. Atmos. Chem. Phys. 2010, 10, 7439-7456. [CrossRef]

17. Riemer, N.; Vogel, H.; Vogel, B. Soot aging time scales in polluted regions during day and night. Atmos. Chem. Phys. 2004, 4, 1885-1893. [CrossRef]

18. Bohren, C.F.; Huffman, D.R. Absorption and Scattering of Light by Small Particles; John Wiley \& Sons: Hoboken, NJ, USA, 2008.

19. Mätzler, C. MATLAB Functions for Mie Scattering and Absorption, Version 2. IAP Res. Rep. 2002, 8, 9.

20. Liu, C.; Panetta, R.L.; Yang, P. The Influence of Water Coating on the Optical Scattering Properties of Fractal Soot Aggregates. Aerosol Sci. Technol. 2012, 46, 31-43. [CrossRef]

21. Massabò, D.; Caponi, L.; Bernardoni, V.; Bove, M.C.; Brotto, P.; Calzolai, G.; Cassola, F.; Chiari, M.; Fedi, M.E.; Fermo, P. Multi-wavelength optical determination of black and brown carbon in atmospheric aerosols. Atmos. Environ. 2015, 108, 1-12. [CrossRef]

22. Guo, X.; Nakayama, T.; Yamada, H.; Inomata, S.; Tonokura, K.; Matsumi, Y. Measurement of the light absorbing properties of diesel exhaust particles using a three-wavelength photoacoustic spectrometer. Atmos. Environ. 2014, 94, 428-437. [CrossRef] 
23. Nakayama, T.; Sato, K.; Matsumi, Y.; Imamura, T.; Yamazaki, A.; Uchiyama, A. Wavelength and NOx dependent complex refractive index of SOAs generated from the photooxidation of toluene. Atmos. Chem. Phys. 2013, 13, 531-545. [CrossRef]

24. Adachi, K.; Buseck, P.R. Internally mixed soot, sulfates, and organic matter in aerosol particles from Mexico City. Atmos. Chem. Phys. 2008, 8, 6469-6481. [CrossRef]

25. Adachi, K.; Zaizen, Y.; Kajino, M.; Igarashi, Y. Mixing state of regionally transported soot particles and the coating effect on their size and shape at a mountain site in Japan. J. Geophys. Res. Atmos. 2014, 119, 5386-5396. [CrossRef]

26. Li, J.; Anderson, J.; Buseck, P. TEM study of aerosol particles from clean and polluted marine boundary layers over the North Atlantic. J. Geophys. Res. 2003, 108. [CrossRef]

27. Scarnato, B.V.; Vahidinia, S.; Richard, D.T.; Kirchstetter, T.W. Effects of internal mixing and aggregate morphology on optical properties of black carbon using a discrete dipole approximation model. Atmos. Chem. Phys. 2013, 13, 5089-5101. [CrossRef]

28. Andreae, M.O.; Gelencsér, A. Black carbon or brown carbon? The nature of light-absorbing carbonaceous aerosols. Atmos. Chem. Phys. 2006, 6, 3131-3148. [CrossRef]

29. Alexander, D.T.; Crozier, P.A.; Anderson, J.R. Brown carbon spheres in East Asian outflow and their optical properties. Science 2008, 321, 833-836. [CrossRef]

30. Smyth, K.C.; Shaddix, C.R. The elusive history of $\mathrm{m} \sim=1.57-0.56 \mathrm{i}$ for the refractive index of soot. Combust. Flame 1996, 107, 314-320. [CrossRef]

31. Chen, L.; Jiang, Y.; Sun, Y.; Gao, X.; Cen, K. Analysis of Absorption and Scattering Properties of Water Host Haze Droplet with Insoluble Solid Inclusion. Chin. J. Lasers 2015, 234-241. [CrossRef]

32. Lang-Yona, N.; Abo-Riziq, A.; Erlick, C.; Segre, E.; Trainic, M.; Rudich, Y. Interaction of internally mixed aerosols with light. Phys. Chem. Chem. Phys. 2010, 12, 21-31. [CrossRef] [PubMed]

33. Bulatov, V.; Fisher, M.; Schechter, I. Aerosol analysis by cavity-ring-down laser spectroscopy. Anal. Chim. Acta 2002, 466, 1-9. [CrossRef]

34. Kirchstetter, T.W.; Novakov, T.; Hobbs, P.V. Evidence that the spectral dependence of light absorption by aerosols is affected by organic carbon. J. Geophys. Res. Atmos. 2004, 109. [CrossRef]

35. Schnaiter, M.; Linke, C.; Möhler, O.; Naumann, K.H.; Saathoff, H.; Wagner, R.; Schurath, U.; Wehner, B. Absorption amplification of black carbon internally mixed with secondary organic aerosol. J. Geophys. Res. Atmos. 2005, 110. [CrossRef]

36. Liu, D.; Whitehead, J.; Alfarra, M.R.; Reyes-Villegas, E.; Spracklen, D.V.; Reddington, C.L.; Kong, S.; Williams, P.I.; Ting, Y.; Haslett, S. Black-carbon absorption enhancement in the atmosphere determined by particle mixing state. Nat. Geosci. 2017, 10, 184. [CrossRef]

37. Li, K.; Chen, L.; Han, K.; Lv, B.; Bao, K.; Wu, X.; Gao, X.; Cen, K. Smog chamber study on aging of combustion soot in isoprene/SO2/NOx system: Changes of mass, size, effective density, morphology and mixing state. Atmos. Res. 2017, 184, 139-148. [CrossRef]

(C) 2020 by the authors. Licensee MDPI, Basel, Switzerland. This article is an open access article distributed under the terms and conditions of the Creative Commons Attribution (CC BY) license (http://creativecommons.org/licenses/by/4.0/). 